\title{
ADAPTING THE TOOL: A HISTORIC BUILDING INFORMATION MODEL (HBIM) OF SENHORA DA PIEDADE DA CAPARICA
}

\author{
Jesse Rafeiro $^{(1)}$, Ana Tomé (2) \\ (1) Carleton Immersive Media Studio: Carleton University, Ottawa \\ (2) Instituto Superior Técnico: Universidade de Lisboa, Lisboa
}

\begin{abstract}
Once a place of silence and solitary contemplation for a group of Franciscan friars known as Capuchos, Nossa Senhora da Piedade da Caparica (1558) today is in a state of confusion about the original configuration of its spaces. Following a major renovation project in the 1950 s and a lack of documentation throughout its life, the convent seeks to better understand its past and its continued role within the municipality of Almada. Since no record drawings or descriptions of the building exist prior to the renovation, an interdisciplinary, mixed-methodological research approach was taken to generate a HBIM reconstruction of the convent. The HBIM will serve as a record of the building's modifications across time as well as an as-found record of the building to date for use into the future.

This paper focuses on one aspect of this overall research project by presenting the modelling methods used to overcome the limitations of BIM software (Revit 2020) for heritage. Since the software was designed to facilitate the construction of new buildings, a high level of effort is needed to adapt the tool to fit the irregularities and asymmetries of heritage. Focusing on the ornate $17^{\text {th }}$ century facade -subjected to years of weathering and renovation campaigns-along with the entranceway and choir of the church, this paper addresses techniques for modelling a range of conditions typical to those found in heritage in Portugal. The paper will address methods for modelling irregular geometries such as wall deviations, arched ceilings, inconstancies in wall profiles and methods for modelling custom window families from point cloud data.
\end{abstract}

\section{Introduction}

In recent years, Building Information Modelling (BIM) software has been adopted to historic buildings for a variety of purposes across the world, including facilities management and cultural heritage preservation of both tangible and intangible values. Although there are a variety of approaches and potential outputs, the range of activity corresponding to the use of 
BIM software toward the recording of heritage buildings can be grouped under the term Historic Building Information Modelling (HBIM). In his early definition of HBIM, Murphy (2009), described it as a new way of modelling heritage, beginning with survey data, terrestrial laser scanner data and digital images that can be combined through a range of software programs [1]. Since then however, Historic England has alluded to a broader definition of the aplicability of BIM to heritage, suggesting its use for both tangible and intangible values along with geometric and non-geometric information [2]. This type of information could include sourced documents, material knowledge and past phases of construction that could all be linked together into one model platform where simulation of the future of the building is also a possibility.

While it has been proven to be a difficult task to create guidelines for BIM practices internationally within the architecture, engineering and construction / facilities management (AEC/FM) industry, an even greater challenge has been to create guidelines for HBIM where heritage constructions face several scenarios not within the range of concerns involved in the design of new buildings such as deformations and inconsistencies of construction. The disagreement between HBIM standards and classifications has been dicussed by several authors $[3,4,5]$ and several publications stress the need for guidlines specific to BIM and heritage $[2,6,7]$.

\section{Background to the HBIM in Caparica}

Today there are many uncertainties regarding the original configuration of the spaces of the Convent of Nossa Senhora da Piedade da Caparica following an extensive renovation project that took place in the 1950s and due to a lack of documentation throughout its lifespan. Presently, the convent serves the community of Almada as a space for recitals, concerts, wedding receptions and other social events that although fruitful to the community, mask its original conception as a place of silence and solitary contemplation for a small group of Franciscan friars. A more thorough understanding of the building's history is today sought for the convent to better understand its past and plan its continued role within the municipality. The role of a HBIM within the context of Caparica is to help achieve a better knowledge about the history and original condition of the building by visualizing how it could have been in key phases of its history prior to the 1950s while supporting its programming and maintenance into the future. In close approximation to the definition of HBIM provided by Historic England [2], the model will aim to incorporate all materials pertinent to the history of the building together in one model as a form of digital archive. Since uncovering its history requires a non-invasive, non-archaeological approach that does not disrupt current building functions, reliance on other forms of evidence such as studies of other convents of the same Arrábida province along with the study of other historic texts and photographs is necessary. To achieve this, the overall project employs an interdisciplinary, mixed-methodological research approach to promote the scientific validation of the virtual reconstruction of the convent in two key phases prior to the 1950s: 1558 and 1630. The methodology to date has also prompted a range of interrelated research outputs helpful to historians and the public in understanding the history of the convent in Caparica and other provinces belonging to the Arrábida history in a broader sense. The range of datasets used to make the conclusions - including historic text, historic photographs, photogrammetric models, point cloud data and drawings - will all be sourced within the HBIM. 


\section{Modelling to Point Cloud}

The following subsections provide descriptions and illustrations of approaches undertaken to model the HBIM of the $17^{\text {th }}$ century facade of Nossa Senhora da Piedade da Caparica in Revit 2020. The phase of the modelling described below focuses exclusively on the present condition of the building as captured through a combination of point cloud data for the exterior of the main facade and photogrammetry of the interior spaces behind the facade.

The goal of this phase of the research was to refrain from using additional non-BIM software to assist in the modelling of the complex elements in order to see what results could be achieved within the limitations of the tool. Other approaches to HBIM have adopted other programs such as Rhinoceros into the modelling of irregular geometry [8] where geometry is imported from one program to another. Other authors have reviewed the current state of HBIM providing various examples of automated approaches that although could hasten modelling processes, also require additional software beyond BIM [4]. In the case of using additional tools, complications can arise when geometry needs to be adjusted within the BIM at a later date for example, in cases where new material information is acquired for a ceiling element and the thickness of the object needs to change - because it requires a remodelling and reexporting rather than adjustment within the BIM program. Furthermore, in the case of the convent in Caparica, very few elements repeat, so the use of automatic tools has less advantage.

The elements described below have been chosen because they correspond to common scenarios found across heritage buildings in Portugal. The sections will illustrate the following elements: wall deviations, arched ceilings, irregular wall-profiles and windows.

\subsection{Wall deviations}

As they morph to the effects of weathering and time, heritage buildings are often full of irregular and warping walls. When modelling to point cloud, whether in plan or section, heritage walls tend to not follow the orthogonal grid Revit software was optimized for in order to streamline new constructions. Additionally, Revit creates an automatic join between two or more walls by default in cases where walls touch or are near enough which can cause unwanted geometries to arise. In cases where walls meet non-orthogonally, it was found that it is best to use the unjoinwall tool to disallow the default wall connections of Revit and to manually re-join the walls by embedding them into one another. Once the desired arrangement of walls is achieved the walls can be manually joined using the regular join geometries tool. Figure 1 shows an example where the outer face of the exterior wall was modelled and fitted to point cloud as one wall element, while many individual walls for each of the interior spaces corresponding to the facade where modelled as separate wall elements and manually joined. 

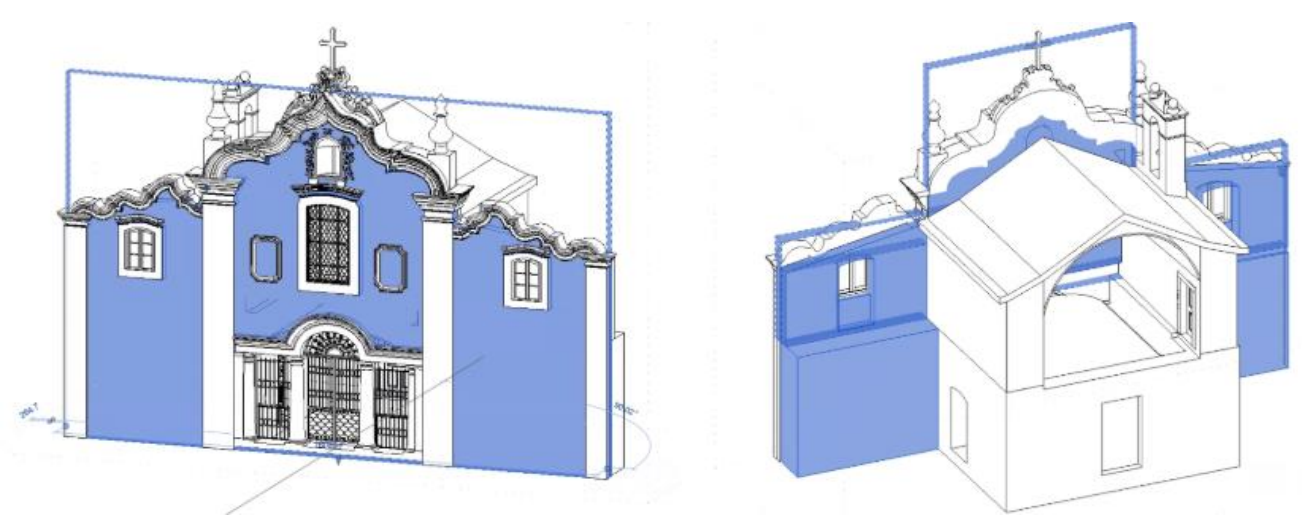

Figure 1: A single outer wall of the facade is joined to a series of walls of varies thicknesses for the interior spaces.

When observing the point cloud of a heritage building in section, walls also tend to not be perfectly straight. In this type of situation, it was found possible to model this type of irregularity by using the in-place massing tool and applying a wall by face that can capture the irregularity. The disadvantage found with this is approach is that it would greatly increase the overall modelling time and make future adjustments such as the hosting of window families and other objects more difficult on a non-planar surface. The decision was made to align as best as possible the straight wall to the point cloud, making sure to annotate this discrepancy within the notes of the modelled object as shown in Figure 2.

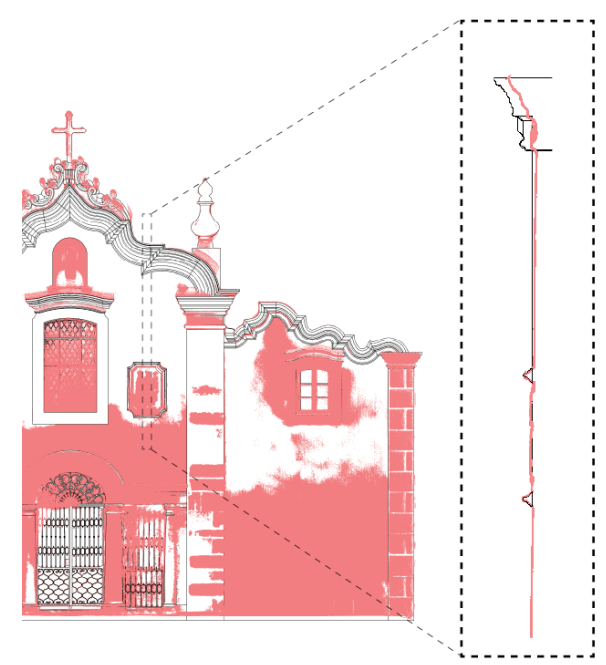

Figure 2: Overlay of model (black lines) to point cloud date (red) to show vertical deviation at the top of the wall.

\subsection{Arched ceilings}

The default option for modelling ceilings in Revit is limited to flat planes that slope. Commonly, in heritage buildings, and in most cases of religious buildings, ceilings are curved or arched. In order to overcome this limitation, an alternative approach using the model component in-place tool was explored that makes available a full range of modelling tools: extrusions, blends, revolves, sweeps, and sweep blends (as both solid and void forms). When modelling a component in-place one can choose a ceiling as a category of classification for the particular 
element. For the ceiling in the space of the entrance, a blend with profiles traced from the point cloud at both ends of the ceiling where it meets the wall was used to define the shape. After, a perimeter void in the shape of the perimeter walls of the room was added to ensure the ceiling remained flush with the walls (Figure 3). This void addition was needed since none of the walls around the ceiling were perfectly orthogonal.

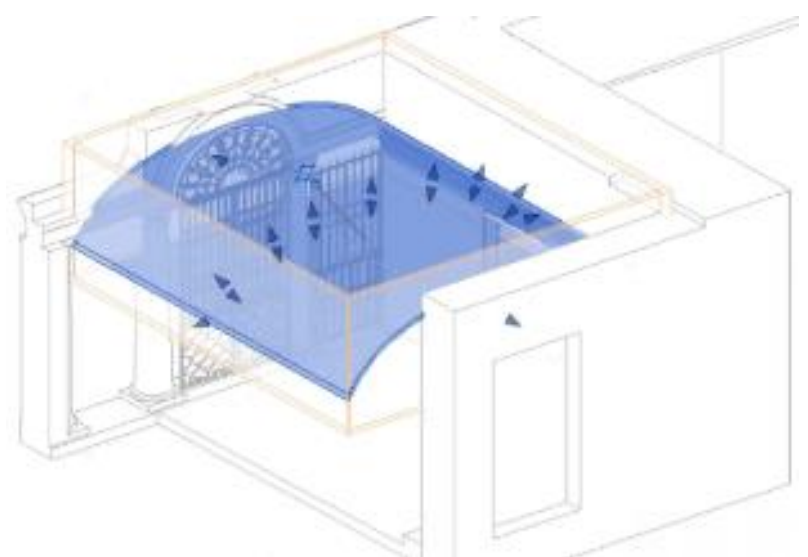

Figure 3: Model in-place arched ceiling with void geomtery to cut ceiling evenly with walls.

\subsection{Irregular wall profiles}

The default Revit tool used to add cornices and profiles to walls is limited to orthogonal planes that run vertically and horizontally across a wall surface. In a similar manner as described in the section above on arched ceilings, the irregular wall profiles required the use of the range of tools available within the model component in-place function. Because of the extremety of the profile in this scenario that runs organically along the top of the facade, a series of errors resulted from attempts to model the profile as a single sweep element. Instead, it was found that the geomtery needed to be split up into a series of fragments with individual voids cutting the excess geometry of each segment at a time.
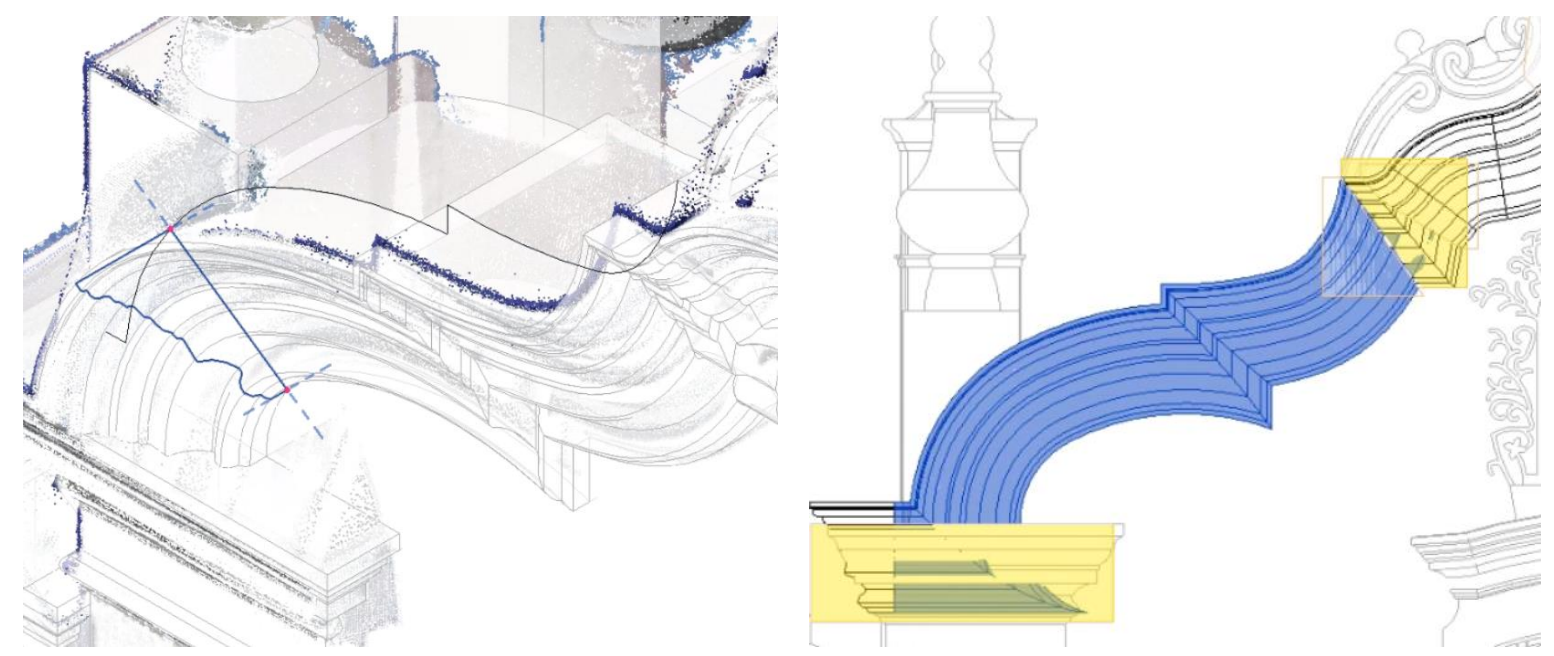

Figure 4: Profile traced from point cloud for model in-place wall profile (left) segment of model in-place wall profile (blue) showing locations of void cuts (yellow) to cut excess geometry (right). 


\subsection{Windows}

In cases where windows do not repeat in various instances across a building it has been found that modelling a window component in-place, non-parametrically and directly to the point cloud data is an effective approach. Another parametric approach applicable to modelling many windows of the same type within Revit has been explored in previous research [9]. In the method chosen for Caparica, a series of voids are cut from the wall and a series of solid elements and profiles infilled to build-up the desired geometry. Following the modelling in-place, it is aftewards possible to export the geomtery as a Revit family for import back into the Revit project by grouping the elements within the in-place model editor and saving all selected objects as a library group in the save as command. When doing this, it should be noted that some additionally editing in the Revit family will be be necessary, such as establishing and locking geometry to reference planes to prevent shiting parts. In current versions of Revit, point cloud data can not be brought into the family editor which makes it difficult for families to match the point cloud data of the project. By modelling the directly to the pointcloud within the Revit project instead of within the Revit family editor, the modeller can avoid the difficulty of translating the point cloud data into 2D line tracing or other means in order to model accurately within the family editor. This same approach was also found relevant to a variety of details such as wall based ornaments or alters that carve partially into the wall.
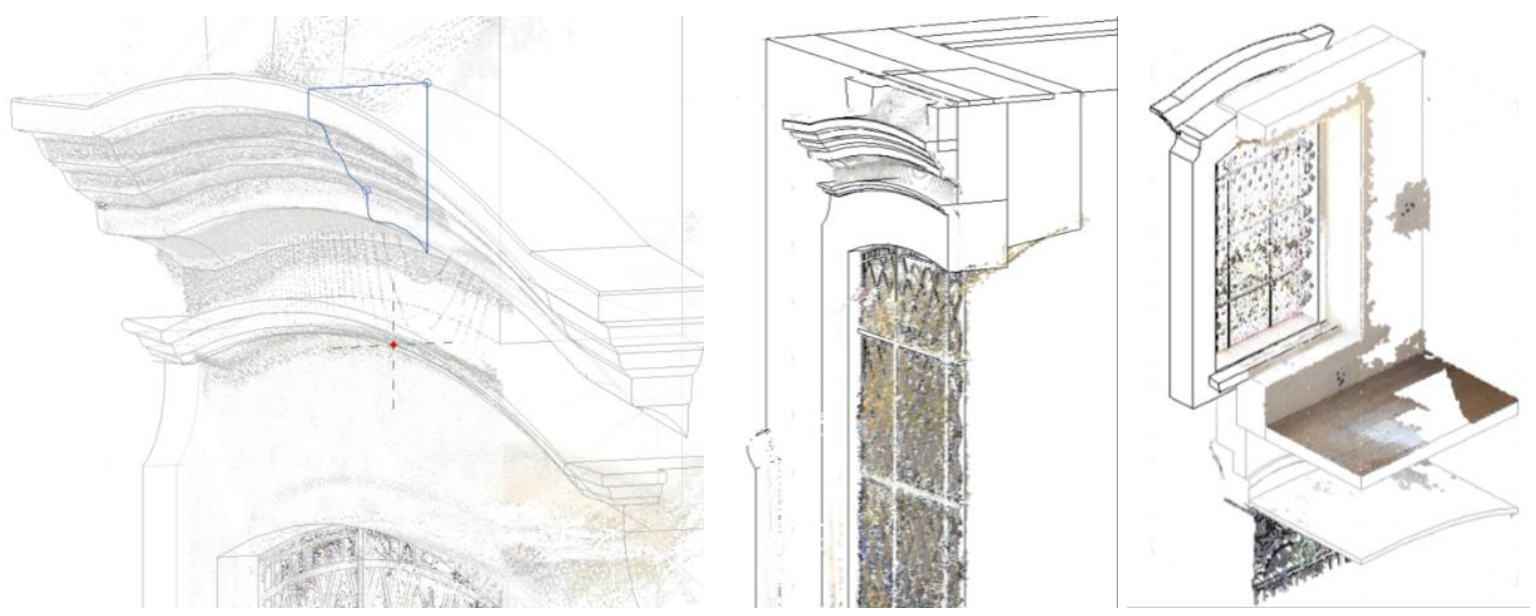

Figure 5: Tracing profile from point cloud for a model in-place window (left) sections through final modelled window showing solid geomatry and void cuts in the wall (middle and right).

\section{Conclusions}

While there appears to be many limitations to the use of Revit for heritage buildings, it has been possible to adopt a range of tools within the program toward uses that may not have been originally intended in the facade of the convent in Caparica (Figure 6). Modelling components such as ceilings and wall profiles as in-place components instead of using default tools permits the use of more advanced modelling options applicable to heritage. Furthermore, these in-place models still allow the classification of elements according to their proper categories. Having the option to also export in-place geometry (modelled to point cloud) from within a Revit project and import it into a conventional Revit family also provides a sufficient alternative 
considering point cloud data is not currently importable into Revit families. Other techniques described in this paper, such as splitting wall geometries or wall profile geometries into many pieces in the model despite their uniformity in the real building are limitations that must be evaluated according to the specific scenario and can perhaps only be dealt with through trial and error or with enough familiarity with the software.

In the next phase of work, the rest of the HBIM of Nossa Senhora da Piedade da Caparica asfound will be modelled according to further laser scanning surveys of the exterior and interior rooms as well as drone photogrammetry for the roof. Following documentation and processing of the data, modelling methods for other typical heritage elements such as terracotta roofs, railings, stairs, and selection of different ceiling types will be explored.

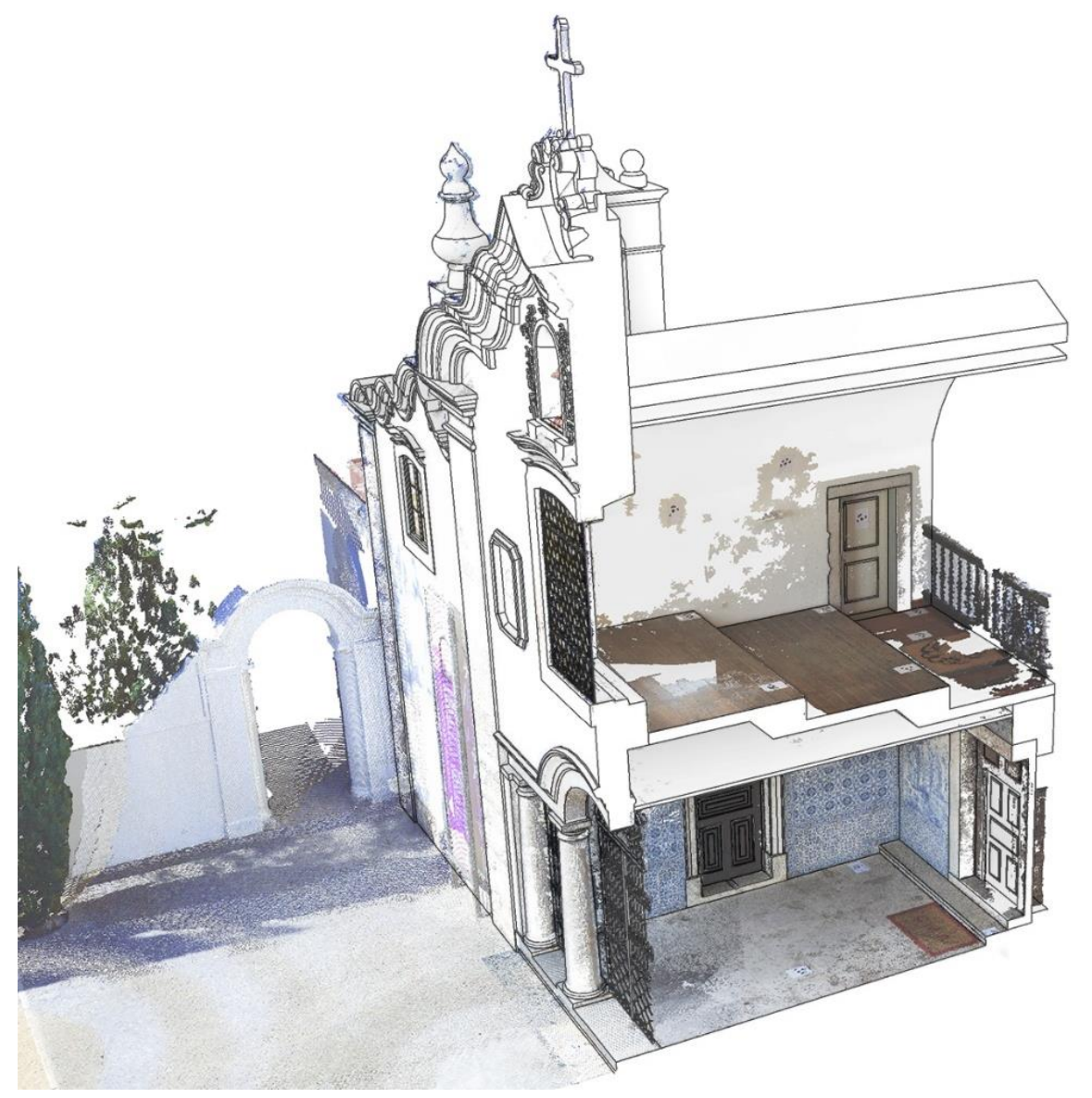

Figure 6: Model of the facade of Nossa Senhora da Piedade da Caparica.

\section{Acknowledgments}

The activity presented in this paper was made possible by funding from the "New Paradigm / New Tools for Architectural Heritage in Canada" training program funded by the Social Sciences and Humanities Research Council (SSHRC) as well as by the support of the Municipality of Almada (Câmara Municipal de Almada). 


\section{References}

[1] Murphy, M., McGovern, E., and Pavia, S., "Historic building information modelling (HBIM)" Structural Survey, vol. 27, no. 4, August 2009, pp. 311327.

[2] Historic England 2017, BIM for Heritage: Developing a Historic Building Information Model. Swindon. Historic England.

[3] Hichri, N., Stefani, C., De Luca, L., and Vernon, P., "Review of the "As Built BIM" Approaches," International Archives of the Photogrammetry, Remote Sensing and Spatial Information Sciences, vol. 40, no. 5, 2013, pp. 107-112.

[4] Dore, C., and Murphy, M. 2017, "Current state of the art historic building information modelling," The International Archives of the Photogrammetry, Remote Sensing and Spatial Information Sciences, vol. 42, no. 2, 2017, pp. 185-192. doi:10.5194/isprs-archivesXLII-2-W5-185-2017.

[5] Chow, L., Graham K., Grunt T., Gallant M., Rafeiro J., and Fai. S., "The Evolution of Modelling Practices on Canada's Parliament Hill: An Analysis of Three Significant Heritage Building Information Models (HBIM)," The International Archives of the Photogrammetry, Remote Sensing and Spatial Information Sciences, vol. 42, no. 2, 2019, pp. 419-426.

[6] Historic England 2019, BIM for Heritage: Developing an Asset Information Model. Swindon. Historic England.

[7] Plowman Craven's BIM Survey Specification and Reference Guide (2015).

[8] Oreni, D., Brumana, R., Della Torre, S. Banfi, F., Barazzetti, L., and Previtali, M., "Survey Turned into HBIM: The Restoration and the Work Involved Concerning the Basilica Di Collemaggio after the Earthquake (L'aquila)" ISPRS Annals of the Photogrammetry, Remote Sensing and Spatial Information Sciences, vol. 2, no. 5, 2014, pp. 267-273.

[9] Fai, S., Rafeiro, J. "Establishing an Appropriate Level of Detail (LoD) for a Building Information Model (BIM) - West Block, Parliament Hill, Ottawa, Canada," ISPRS Annals of Photogrammetry, Remote Sensing and Spatial Information Sciences, vol. 2, no. 5, 2014, pp. 123-130. 